\title{
Willy Servais and Tamás Varga - A Belgian- Hungarian perspective on teaching school mathematics
}

\section{DIRK DE BOCK}

\begin{abstract}
Willy Servais and Tamás Varga had a major influence on the development of mathematics education during the 1960s and 1970s, both in their home countries and internationally. In 1971 they jointly published Teaching School Mathematics-A Unesco Source $B o o k$, a review of curriculum reforms that were under way in different parts of the world. The book, presenting several modern syllabuses as well as examples of classroom techniques and segments of teacher-student dialogues, provided an often consulted guide to the field of mathematics education. We re-read this book and in this way acquire a unique insight into the modernization efforts of school mathematics during the 1960s and early 1970s. We take this opportunity to discuss the sometimes partly divergent views of Servais and Varga on modern mathematics education as reflected in this book.
\end{abstract}

Key words and phrases: curricular reform, historical analysis, modern mathematics, school mathematics, Tamás Varga, views on mathematics education, Willy Servais.

ZDM Subject Classiffication: A30.

Copyright c 2019 by University of Debrecen 


\section{Introduction}

Various parallels can be drawn between the personal lives and professional careers of the Belgian Willy Servais and his six-year younger Hungarian colleague Tamás Varga. Both 'experts in mathematics education', brought up in the pre-World War II period, had a definite influence on the development of mathematics education during the 1960s and 1970s, both in their home countries and at the international level. Nationally, they were involved in the development of new mathematical curricula and textbooks. Internationally, their names are inextricably linked to CIEAEM, the International Commission for the Study and Improvement of Mathematics Teaching, the main forum for all those who were actively involved in research and development of mathematics education at that time. A major joint achievement was the publication of Teaching School Mathematics in 1971, a review of curriculum reforms that were under way in different parts of the world. Servais and Varga have been part of, respectively, the first and the second editorial board of Educational Studies in Mathematics, the renowned international journal in mathematics education, founded by Hans Freudenthal in 1968.

Servais and Varga were children of their time, a time in which the so-called 'modern mathematics' dominated Europe and other parts of the world. They actively participated in the early stages of this reform movement and developed syllabuses for the teaching of mathematics using sets, logic and other homogeneous modern ideas. However, they never fell into dogmatism and always put the pedagogical aspect first.

This paper is structured as follows. We first provide a short biography of the Belgian Willy Servais, an eminent figure in mathematics education who is less well known in Hungary. Servais and Varga probably met for the first time at the International Symposium on School Mathematics Teaching in Budapest (1962). In a second part, we briefly discuss the conclusions and recommendations of that symposium which were strongly influenced by what we would like to call the 'FrenchBelgian view' on modern mathematics. Later in his career, Varga will take a critical stance towards this view. Thirdly, we consider the Hungarian experiments led by Varga during the 1970s. In these experiments, modern mathematical topics, such as logic and probability, were integrated in a curriculum that was structured spirally. We conclude with a re-reading of Teaching School Mathematics (1971), a joint publication by Servais and Varga, and take the opportunity to discuss both mathematics educators' partially divergent views on teaching school mathematics. 


\section{Willy Servais}

Willy Servais (Nivelles, Belgium, 1913 - Budapest, 1979), studied at the Royal Athenaeum of his home town and went on to study mathematics at the Free University of Brussels where he graduated in 1936 and also obtained his teacher's degree. One year later, he started to teach at the Athenaeum in Morlanwelz, a secondary school with a secular background in the Walloon part of Belgium. At the outbreak of the Second World War, Servais was enlisted in the Belgian army as an officer and subsequently deported to a German prisoner of war camp near the current GermanPolish border. During his time as a prisoner, he acted as a mathematics teacher for his fellow prisoners, who wished to prepare for their university exams. He also organized small seminars on advanced mathematics and gave lectures. With the help of the Red Cross, Servais was able to obtain several works on mathematics, logic and methodology, in particular by the Swiss psychologists and philosophers Jean Piaget and Ferdinand Gonseth. Upon his return to Belgium in 1945, Servais resumed his work in Morlanwelz. In 1951, he also started to teach a course on logic at the Higher Institute for Pedagogy, a teacher training college also located in Morlanwelz, which in 1965 was incorporated in the University of Mons.

Servais entered the international arena in 1951; he was invited to an international meeting held in the Flemish municipality of Keerbergen and organized by Caleb Gattegno (1911-1988), a mathematician and psychologist at the University of London. This and two similar meetings led to the creation in 1952 of the CIEAEM, the International Commission for the Study and Improvement of Mathematics Teaching and Servais was one of the 'founding members' (Bernet \& Jaquet, 1998). Servais quickly acquired a central position within that group, collaborating closely with Gattegno in the organization of the meetings. In 1956, he was nominated as European secretary of the CIEAEM and four years later as its secretary, a position he held until he died in 1979. He has been described as the 'soul of the meetings' of the CIEAEM, always providing 'brilliant syntheses' at the end of each meeting.

To ensure a structural relation between the work of CIEAEM and the community of Belgian mathematics teachers, Servais surrounded himself with some like-minded colleagues to found in 1953 the Belgian Society of Mathematics Teachers. The impact of Servais, who served as president until 1969, was immense: He was the undisputed leader of the Society during the 1950s and 1960s. In 1953 the Society also started 
publishing Mathematica \& Paedagogia, a quarterly journal for its membership. During the 1950s, due to Servais' versatile contacts, the journal became a main international forum of ideas and proposals related to the teaching of mathematics, in particular by members of CIEAEM.

The theoretical debates within CIEAEM and the Belgian Society of Mathematics Teachers also led to practical reform strategies. In August 1958, together with Frédérique Lenger, Servais compiled the draft of a concrete program for the teaching of 'modern mathematics', that was subsequently tested in two schools during the following school year, arguably the first attempt to teach modern mathematics in Europe. To report on these actions, Servais was invited to lecture at the Royaumont Seminar on New Thinking in School Mathematics in 1959 on which the international 'modern mathematics' movement was officially launched. He was also appointed as an international expert for the Organisation for European Economic Cooperation (OEEC) to prepare a modern syllabus on secondary school mathematics for students in scientific study streams. The syllabus was adopted at a follow-up meeting in Dubrovnik in 1960 and subsequently widely distributed. Over the next years, Servais collaborated with Georges Papy's Belgian Center for Mathematics Pedagogy to work out a comprehensive syllabus for a new mathematical curriculum for Belgian secondary schools, the basic guidelines of which he presented at the International Working Session on New Teaching Methods for School Mathematics, organized by OEEC in Athens in 1963.

From that time, Servais became recognized internationally as one of the main experts in mathematics education and was often invited to lecture and to present reports at conferences. Howard Fehr invited him to teach at Columbia University Teachers College in New York from 1964 to 1969, and in 1966 he opened a teacher training course in Montreal and Sherbrooke. Servais contributed to the debates in the International Commission on Mathematical Instruction, wrote articles for ICMI's UNESCO volumes and actively participated in its new conference series ICME, the International Congress on Mathematical Education. Servais passed away in 1979 in Budapest, a few days after he had participated in the $31^{\text {st }}$ CIEAEM meeting in Veszprem.

Servais' amiable character allowed him to remain untouched by the many controversies which divided the international community during the 1960s and 1970s. Freudenthal described the relationship with his Belgian colleague as follows: "Never 
in my life, with people I met, was friendship and profound disagreement more closely knitted than in my relation with Servais" (quoted by La Bastide-van Gemert, 2015, p. 349).

\section{The UNESCO symposium in Budapest}

Servais and Varga were both closely involved in the International Symposium on School Mathematics Teaching, organized by the Bolyai János Society of Mathematics and by UNESCO in Budapest (August 27 - September 8, 1962). Servais was appointed 'chief rapporteur' of that meeting and Varga had prepared one of the preparatory discussion guides (Varga, 1962). Seventeen countries were represented at the symposium; for Belgium, also the more radical reformer Georges Papy participated (Figure 1).
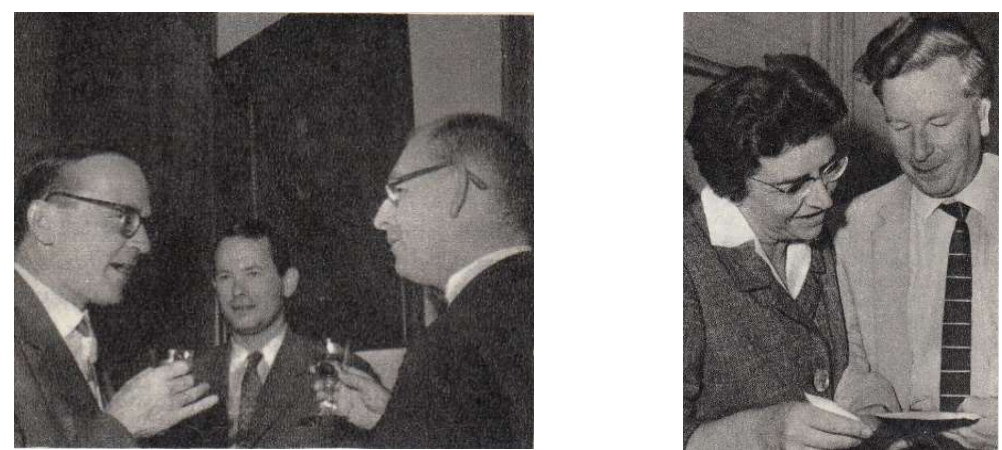

Figure 1. Left: György Hajós (symposium chair, Hungary) and Georges Papy (Belgium) exchange their points of view. Right: Magda Jóboru (president of the Hungarian National

Commission for UNESCO) and Geoffrey Matthews (UK) (photos: Ferenc Vigovszki)

The conclusions and recommendations of the symposium, which were first written in French, were translated into English and included in the official report (Hungarian National Commission for UNESCO, 1963). They strongly reflect the 'French-Belgian' or 'structuralist' view on modern mathematics. More specifically, 
some statements in the official report clearly show the influence of Papy, e.g., "It has been shown that children find greater interest in mathematics when it is presented to them from the earliest stage in its modern vocabulary and form" (p. 11). Basically, a 'structuralist' view on mathematics education means that a model for the science of mathematics, the model developed by the Bourbaki group, is used for developing mathematics education. Papy formulated this as follows:

Euclid's Elements exposed the basic mathematics of his time, about 300 years before J.-C. The monumental work of Nicolas Bourbaki presents, at the highest level, the basic mathematics of today. The "MMs " [= Papy's textbook series] want to expose the Elements of today's basic mathematics for adolescents ... and people of any age and schooling who wish to initiate themselves in the mathematics of our time. (Papy, 1967, p. vii)

From a 'structuralist' point of view, starting points for mathematics education are basic logical and mathematical structures, and the method is a strictly deductive one. The underlying rationale is more or less as follows: If we start from basic, abstract and empty concepts, such as sets and relations, and we then gradually introduce the more concrete and rich concepts, using a clean deductive method, then students will be better able to understand and to appreciate mathematics.

Hence, Belgian mathematics courses of the late 1960s and 1970s started with sets and relations; they mainly had a role as basis of the mathematical edifice that would be further built up in subsequent years. Venn and arrow diagrams, the corresponding representations, were given a privileged status: Students were encouraged to visualise any mathematical problem or situation through these tools; the use of other, selfconstructed representations was discouraged. Some symbolism of mathematical logic was introduced in relation to set theory. In the upper secondary level, a course in mathematical logic, even in a formalized form, was given. This course had no strong connections with other curricular topics, it was given for its own sake and to be applied in analysis, to rigorously define the concepts of continuity and limit in a topological environment (De Bock \& Vanpaemel, 2019).

A quarter of a century later, Varga declared that, during the two weeks of the Budapest symposium, his views on mathematics learning broadened more than during years and even decades before (Varga, 1988). But he took a critical stance towards the prevailing 'structuralist' view on mathematics education at the symposium. He admitted that he became "over-enthusiastic and prone to biased ideas" and that "some 
of us tended to detach ourselves from the firm ground of reality, that of the schools and of the society" (p. 292).

\section{A Hungarian view on modern mathematics}

Although the younger Tamás Varga was not insensitive to the charms of 'FrenchBelgian style' modern mathematics, his ideas were deeply rooted in the Hungarian mathematical tradition and culture (Gosztonyi, 2016), and were sometimes diametrically opposed to the structuralist view on mathematics education. In the reform movement he led in Hungary during the 1970s, 'sets and logic' also played an important role. However, the approach was completely different from how these topics were dealt with in Belgium at that time (see above). In the Hungarian approach, 'sets and logic' was one of the five basic topics; the other four were 'probability' with combinatorics and descriptive statistics included, 'arithmetic and algebra' (integrated to a high degree), 'sequences and functions' (conducting to analysis), and 'geometry and measuring', but each of these topics was worked out for all classes, for ages from 6 to 14 (Halmos \& Varga, 1978; Varga, 1972).

These topics were not structured according to some model derived from the science of mathematics, but were integrated in a learning trajectory: At each age level, it was considered what of, for instance, probability or combinatorics, can be taught and how it can be done. A specific mathematical content can be studied and 'known' at different levels; the idea was to return to the same topics several times, each time at a higher level. In other words, the curriculum in Hungary was structured spirally, both by mathematical and psychological arguments. So, for instance, the topic 'sets and logic' was not intended as a 'foundation' for the other topics (and thus preceding the other topics), but as a recurring topic and tool to clear thinking and to mathematize. Looking in more detail, 'sets and logic' in the Hungarian experiments led by Varga were used to create challenging activities and reasoning tasks for students of different ages; there was no attempt to prematurely formalize.

As far as we know, this way to deal with typical 'modern mathematics' subject matter was not criticized later, at least not on a large scale, and in retrospect the reform movement in Hungary was not considered a failure. 


\section{Re-reading Teaching School Mathematics}

Following the UNESCO symposium in Budapest, Servais and Varga were asked to edit and partly write Teaching School Mathematics, a survey of new approaches to mathematics teaching in many countries of the world. As an early reviewer wrote: "It is the kind of book that should be kept open on the desk for browsing, and in which each re-reading will turn up nuggets previously overlooked" (Scott, 1973, p. 57). We confine ourselves to a few points of view by Servais and by Varga. Some of these illustrate the zeitgeist, others seem to be still relevant today.

It was Servais' belief that curricular topics could be arranged, depending on the needs of the course, in either a logical, a practical or a psychological order. But, in any case, as a result of our improved understanding of mathematical ideas and theories, mathematics had recovered its unity through set theory. Servais was convinced that this basic unity provided the solution to the pedagogy that he had in mind: As the goal of mathematics teaching was to activate the mind of the child towards grasping the mathematical structures in the world around him, it was necessary to define these structures and to make them the backbone of the whole syllabus.

Teaching should proceed in the light of these findings and, using set theory as a basis, should build up a more unified construction, structured by homogeneous modern ideas. It should do this not only to present an authentic, albeit elementary, image of the science of mathematics, but also to develop the psychological ability to use mathematics as a tool in a broader, more deliberate and more effective way. (p. 217)

Varga also elaborated on the role of structure in mathematics education: For him, structure is something that one gradually discovers and learns to appreciate.

In learning mathematics, as in learning a language, use is the best starting point. Few are interested in the structure (mathematical or grammatical) of what they have not experienced in use. If they have, the growing appreciation of the structure is fundamental in promoting correct and efficient use. (p. 14)

About the unifying tendency in mathematics education, Varga warned about an introduction of general concepts without adequate preparation, without sufficient motivation, in an uninspired way. 
An early knowledge of general unifying ideas does not mean a hunt for halfripe abstractions alien to the mind of the child. Rather it amounts to what may be called a striving after 'globality': Instead of starting from the parts and trying to fit them together to a whole, it means going from the whole to its parts. (p. 20)

During the 1960s and 1970s, several curricula and syllabuses were reshaped, but Servais warned that every reform was but a temporary step, which needs to be continuously evaluated and improved upon in a next phase. The rigidness of any curriculum, including the one created by Papy, could not be left unchanged forever. He also put the importance of syllabuses into perspective.

A mathematical education of this kind depends not so much on the syllabus as on teaching method, for it is only good teaching that can make a syllabus meaningful. Let us make no mistake: Any syllabus, however sensible and balanced it is, can degenerate into mere dogma in the hands of a dogmatic teacher. (p. 219)

For his part, Varga emphasized the enjoyment of mathematics, connected with play and fantasy, an idea that is deeply rooted in the tradition of Hungarian mathematics education.

One of the fundamental aims of the present reforms is to help pupils enjoy mathematics, to make them realize its beauty. [...] Essential to this approach is freedom of expression, arising from playful activity. To realize and enjoy the beauty of mathematics, pupils must be given sufficient opportunity for free, playful, creative activity, where each can bring out his own measure of wit, taste, fantasy, and display thereby his personality. (p. 16)

\section{References}

Bernet, T., \& Jaquet, F. (1998). La CIEAEM au travers de ses 50 premières rencontres

[The CIEAEM through its first 50 meetings]. Neuchâtel, Switzerland: CIEAEM. 
De Bock, D., \& Vanpaemel, G. (2019). Rods, sets and arrows. The rise and fall of modern mathematics in Belgium. Cham, Switzerland: Springer.

Gosztonyi, K. (2016). Mathematical culture and mathematics education in Hungary in the XXth century. In B. Larvor (Ed.), Mathematical cultures. Cham, Switzerland: Springer.

Halmos, M., \& Varga, T. (1978). Change in mathematics education since the late 1950s — ideas and realization. Educational Studies in Mathematics, 9(2), 225-244.

Hungarian National Commission for UNESCO (1963). Report of the work of the International Symposium on School Mathematics Teaching. Budapest, Hungary: Akadémiai Kiadó.

La Bastide-van Gemert, S. (2015). All positive action starts with criticism. Hans Freudenthal and the didactics of mathematics. New York, NY: Springer.

Papy, G. (1967). Mathématique moderne 3. Voici Euclide [Modern mathematics 3. Euclid now]. Brussels, Belgium-Montréal, Canada-Paris, France: Didier.

Scott, D. E. (1973). Good for browsing [Review of Teaching School Mathematics]. The Physics Teacher, 11, 56-57.

Servais, W., \& Varga, T. (Eds.) (1971). Teaching school mathematics-A Unesco source book. Middelsex, UK: Penguin Books.

Varga, T. (1962). On some curriculum problems of school mathematics (typewritten text dated May 28, 1962, 35 pages). Paris, France: UNESCO.

Varga, T. (1972). Logic and probability in the lower grades. Educational Studies in Mathematics, 4(3), 346-357.

Varga, T. (1988). Mathematics education in Hungary today. Educational Studies in Mathematics, 19(3), 291-298.

\section{DIRK DE BOCK}

FACULTY OF ECONOMICS AND BUSINESS

KU LEUVEN, BELGIUM

E-mail: dirk.debock@kuleuven.be 